\title{
Nestedness in forest mammals is dependent on area but not on matrix type and sample size: an analysis on different fragmented landscapes
}

\author{
Menezes, JFS.* and Fernandez, FAS. \\ Laboratório de Ecologia e Conservação de Populações, Departamento de Ecologia, Instituto de Biologia, \\ Universidade Federal do Rio de Janeiro, Ilha do Fundão, CP 68020, CEP 21941-590, Rio de Janeiro, RJ, Brazil \\ e-mail: jorgefernandosaraiva@gmail.com \\ Received: February 2, 2012 - Accepted: August 14, 2012 - Distributed: August 31, 2013
}

\begin{abstract}
Nestedness, the pattern in which the species of a species-poor community are a subset of species-rich communities, can provide information regarding species order of extinction, which is vital knowledge for conservation biology. We tested the hypotheses that the nestedness of mammal communities in forest remnants is influenced by sampling effort, mean remnant area, range of remnant areas, matrix type, and presence or absence of forest corridors, and compared the results with multi-taxa reviews. We used 24 published datasets to test this hypothesis and ran simple regressions for each variable. Our results provide evidence that area was the main determinant of nestedness in mammalian communities. We also found a significant effect on the range of areas as measured through area ratio. However we conclude that nestedness is not affected by sample size.
\end{abstract}

Keywords: nestedness, effort; matrix type, forest fragments, mammals, area.

\section{Aninhamento em mamíferos florestais depende da área mas não do tipo da matriz ou do tamanho amostral: uma análise com diferentes paisagens fragmentadas}

\section{Resumo}

Aninhamento, o padrão no qual espécies de comunidades mais pobres são subconjuntos de comunidades mais ricas, pode fornecer informações sobre a ordem de extinção de espécies, conhecimento vital para a conservação. Testamos a hipótese que o aninhamento das comunidades de mamíferos em fragmentos florestais é influenciado pelo esforço amostral, média e variação de área dos fragmentos, assim como pela presença de corredores florestais e pelo tipo de matriz circundante, e comparamos com revisões multi-taxa. Usamos 24 conjuntos de dados publicados para testar essa hipótese. Nossos resultados forneceram evidencia de que a área foi o principal determinante do aninhamento de comunidades de mamíferos. Nós também concluímos que aninhamento não é afetado por esforço amostral.

Palavras-chave: aninhamento, esforço amostral, matriz, fragmentos florestais, mamíferos, área.

\section{Introduction}

The concept of nested subsets (Patterson and Atmar, 1986) proposes that species which form an impoverished insular biota are a non-random subset of the ones found in species-rich biotas. In a perfectly nested structure, all species from poorer communities are present in richer communities, whereas the reverse is not true (Patterson, 1987; Patterson and Atmar, 1986). Although perfect nestedness is seldom found in nature, natural communities are often more nested than what would be expected by chance (Patterson, 1990; Worthen, 2011; Wright et al., 1998), and the degree of nestedness varies among communities (Wright et al., 1998).

Besides true (geographical) islands, nestedness can also be found in fragmented landscapes where this pattern is brought about mostly by extinction after habitat remnants become isolated (Cutler, 1991; Wright et al., 1998). Extinction-generated nested patterns in frag- mented landscapes are of particular interest for conservation, as they imply a predictable order for the loss of species (Ganzhorn and Eisenbeiss, 2001; Martinez-Morales, 2005). Such an order, coupled with inferences on the numbers of species taken from species-area relationships, can be used to predict which species will be lost following an eventual reduction in the area of available habitats (Macdonald and Brown, 1992). Because of this application, understanding what processes affect nestedness in fragmented landscapes is important for conservation (Fischer and Lindenmayer, 2005).

Among the factors which can determine the degree of nestedness, the one which has been studied most often is fragment area. The area of the remnants is expected to be negatively correlated to extinction rates (MacArthur and Wilson, 1967). Therefore, the degree of nestedness generated by extinction would be expected to negatively correlate with fragment area. However, as nestedness can 
only be shown by comparing communities with different richness (and thus fragments with different sizes) within a landscape, the range of differences in size among remnants may influence nestedness. In a wide discrepancy scenario, the smallest fragments would contain a more restricted fraction of the largest fragment's biota than in a low discrepancy situation. Therefore, we expect that nestedness would increase along with fragment size range.

Another factor affecting nestedness in fragmented landscapes is the type of the matrix between fragments. Several studies have pointed to the matrix for its importance in fragmented landscapes (see Prevedello and Vieira, 2009), as the matrix - interacting with the species' features - affects isolation and thus extinction rates (Laurance, 1991; Viveiros de Castro and Fernandez, 2004; Watling and Donnelly, 2006). However, few studies in fragmented areas have considered the importance of the matrix for nestedness (Watling and Donnelly, 2006; Wright et al., 1998).

Two other factors which have seldom been studied as determinants of nestedness are sampling effort and the presence or absence of corridors. Although the effects of these variables on species richness have been studied (Torre et al., 2004), their effects on nestedness have never been tested explicitly. The lack of information about the importance of sampling effort is most concerning, because a small sampling effort would result in a sample bias towards common species, and therefore make community composition similar between sites, thereby decreasing estimated nestedness.

We also addressed the effect of time after isolation on nestedness. We reason that time might affect the nestedness values, as studies indicate that the processes generating nestedness changes through time (Meyer and Kalko, 2008; Watling et al., 2009). We hypothesise that nestedness should be lower in newly fragmented regions, as it tends to lean towards an asymptote.

Although several studies on the determinants of nestedness have been carried out, most of them analysed only a single landscape (e.g. Cutler, 1991; Fischer and Lindenmayer, 2005; Martinez-Morales, 2005; Nupp and Swihart, 2000; Wang et al., 2010). This might produce results that lack generality, which may explain the absence of a general pattern (Wright et al., 1998). Therefore, a comparative analysis of different landscapes could be a more fruitful approach. However, existing reviews went straight for the other extreme of investigating nestedness by pooling data of different taxa and landscape types (Watling and Donnelly, 2006; Wright et al., 1998). Therefore, their results may be of little use in the conservation framework, as they have little applicability for specific taxa. Thus, in this article we address the effect of the variables mentioned above (mean fragment size, variation in fragment size, matrix type, time since isolation, sampling effort and presence of forest corridors) on nestedness, specifically addressing non-volant forest-dwelling mammals on a global scale.

Non-volant mammals in fragmented landscapes are a useful category for our study. They are the second most studied group, regarding the importance of the matrix in fragmented landscapes (Prevedello and Vieira, 2009). Also, most studies on this taxon are based on community richness and composition (Prevedello and Vieira, 2009). Therefore they contain information which can be converted to presence-absence information. Besides, we choose forest fragments due to logistical reasons as well. Forest fragments are usually easily distinguished from the matrix, and in general the species which inhabit the matrix and the forest are different, thus avoiding confounding the communities of both types of habitat.

Summing up, we aim to test if the variables pointed as drivers of nestedness by multi-taxa global and single-taxa local studies have the same effect on a single-taxa global scale. Therefore, we test if the nestedness of non-volant forest mammals is affected by the variables analysed, and compare the results with previous multitaxa reviews (Watling and Donnelly, 2006; Wright et al., 1998).

\section{Materials and Methods}

To analyse the effects of all the variables on the degree of nestedness in fragmented forests, we searched for studies that included information on occurrence and/or abundance of mammals in different fragments to be able to calculate nestedness. We used the ISI Web of Knowledge $^{\circledR}$ and the following searching expressions: (matrix $O R$ community) AND (fragments $O R$ remmants $O R$ patches $O R$ fragmentation) AND mammals. We set all the keywords to be searched in "topic". This search returned c.988 matches.

We considered only forest-dwelling non-flying mammal species in order to reduce specific differences. We considered a landscape, i.e. a set of fragments which the authors analysed together, as our sampling unit. Hence, studies which analysed multiple landscapes contributed with multiple points to our analysis. From each source article, we recorded the analysed variables, whenever this information was available. We excluded any control plots or sampling in continuous forests, due to the following problems. Such sites might have a richer fauna and/or being isolated from the set of fragments. Therefore, we cannot guarantee that they have a non-overlapping set of biomes, and a common biological ancestry. These conditions are fundamental to nestedness (Wang et al., 2010).

To calculate the nestedness of each mammal community we used the NODF metric (Nestedness metric based on Overlap and Decreasing Fill, Almeida-Neto et al., 2008), because NODF is less affected by the size of the presence-absence matrix than other available metrics (Almeida-Neto et al., 2008). The value of NODF was calculated using the software ANINHADO (Guimarães and Guimarães, 2006).

The permeability of a matrix was assessed using a semi-quantitative index. We assigned values from one to six, one being the least permeable matrix and six the most permeable one. As extinction-generated nestedness is ex- 
pected to be related to isolation which in turn depends on matrix permeability, we expected a negative relation between nestedness and this index of permeability. We based our scores on the assumption that the permeability of the matrix is correlated with its structural resemblance to the original forest (Gascon et al., 1999).

We used the following scores to assign a permeability value to a matrix: 1 for an urban or suburban matrix, 2 for pastures, 3 for regular plantations, 4 for shrub vegetation or natural grasslands, 5 for tree plantations and 6 for secondary and regenerating forests. If a matrix had components which fell in two or more different classes, a mean between the indexes was used as the matrix index.

We used three metrics to quantify the effect of area: the mean area of the fragments in each landscape, the size range (area of the largest fragment minus the area of the smallest fragment), and the size ratio (area of the largest fragment divided by the area of the smallest fragment). The two last metrics intended to express the range of fragment areas found in a given landscape. We used size range instead of standard deviation of fragment areas, because many articles only provided the range, allowing only the calculation of a mean and size range. Besides, we also used size ratio because this index has been used in the important study of Wright et al. (1998), and thus it is useful for comparative purposes.

To analyse the effect of the sampling effort, we analysed studies which used trap and/or walked transects as sampling methods. We used trap-nights and kilometers for movement in transects as measures of effort. Other methods were seldom used, and therefore, did not provide enough data to allow statistical inference. We also considered whether the remnants were connected by corridors or not, as a binary variable in the model. We expected that landscapes with corridors would have lower nestedness than the ones without them, as corridors should reduce isolation (Gilbert-Norton, 2010; Rocha et al., 2010; Worthen, 1996).

Not all the articles provided information on all variables. Therefore, model selection with all variables was not possible. Besides, several independent pieces of data correlated with each other (e.g. size measures). Therefore, to avoid a large number of models, with few degrees of freedom, we tested the effect of the independent variable on NODF through simple regressions.

\section{Results}

We obtained 24 articles that had the necessary data (Table 1). The studies were concentrated in South America (34\%), but North America and Asia accounted for a significant contribution ( $21 \%$ each). The least studied region was Europe (8\%). Australia accounted for 13\% of the studies. Most of the matrices were composed by agriculture $(58 \%)$ only. Forests were present in $16 \%$ of matrices, pastures in $12.5 \%$ and urban in $8 \%$. Lastly, Rodentia were the order which were studied the most $(28 \%$ of the studies), followed by Carnivora (13\%) and Insectivora $(12 \%)$. Marsupials were present in $10 \%$ of the studies.
All other orders were present in less than $10 \%$ of the studies.

Our simple regression indicated that only size ratio affected nestedness. We found a negative relationship between area ratio and nestedness (Table 2), the opposite of the pattern found in other studies (Wright et al., 1998). It is worth keeping in mind that our regressions differ in sample sizes as not all articles sampled brought information for all variables.

\section{Discussion}

Our results disagree with the literature. One of the multi-taxa meta-analysis also indicates the absence of relation between matrix type and nestedness (Watling and Donnelly, 2006), contrasting with the importance of matrix for population persistence (Fischer and Lindenmayer, 2005; Viveiros de Castro and Fernandez, 2004). We can conclude that nestedness is not affected by matrix type, in spite of the growing body of evidence in literature that points out the importance of the matrix for persistence and dispersal among populations (Franklin and Lindenmayer, 2009).

The effect of sample size in different landscapes had not been compared yet. To our knowledge, the few studies that evaluated the effect of sample size on nestedness focused on webs of interactions (Nielsen and Bascompte, 2007). Besides, we add to the discussion by providing a test with independent samples, instead of resampling the same community with different effort. We found results similar to previous studies; mean nestedness was not affected by sample size. The explanation provided by Nielsen and Bascompte (2007) can explain the effect on fragments. Even if some specialist species were not sampled, the structure would still be perceived, as richness in larger fragments would still be larger. However, it is important to note that sample size also affects matrix size and fill (Nielsen and Bascompte, 2007). Nestedness metrics answer differently to these characteristics (Almeida-Neto, 2008). Thus, the choice of metric affects the sensitivity of the study to sample size. From AlmeidaNeto (2008)'s correlations, we can infer that standardised NODF is the least sensible metric for sample size, and therefore we recommend it for future studies. This finding also simplifies the complex discussion on null models. Ulrich et al. (2009) pointed out that some null models do consider passive sampling, although it is confused with sampling bias. We now provide evidence that the effect of sampling bias is negligible, therefore models like RANDOM1 (Cutler et al., 1994) are in fact controlling passive sampling and mass effect dynamics. Additionaly, the independence of sampling effort enhances the value of equiprobable null models. Ulrich et al. (2009) pointed out that one of the flaws of this model is its susceptability to sample size. Therefore, our results vindicate methods which had been disregarded for being sample sensitive.

On another topic, our analysis indicates that mean area and size range do not affect nestedness. However, we found a weak negative relationship between area ratio 
Table 1 - Summary of the studies used in this analysis. Sampling effort was measured with the number of individuals captured or sighted. Mean area refers to the mean of the remnants area. Area ratio is calculated as the maximum area divided by the minimum. The matrix perm is a semi-quantitative index of permeability of the matrix surrounding the remnants. Corridors is a categorical variable addressing the presence $(\mathrm{P})$ or absence $(\mathrm{A})$ of corridors. Row nested is the value of the NODF nestedness index, referring only to nestedness between remnants. NA indicates that data is not available.

\begin{tabular}{|c|c|c|c|c|c|c|c|}
\hline Autor & Effort & $\begin{array}{l}\text { Mean area } \\
\text { (ha) }\end{array}$ & $\begin{array}{l}\text { Area ratio } \\
\text { (ha) }\end{array}$ & $\begin{array}{l}\text { Area ampli- } \\
\text { tude (ha) }\end{array}$ & $\begin{array}{c}\text { Matrix } \\
\text { perm }\end{array}$ & corridors? & $\begin{array}{c}\text { Row } \\
\text { nestedness }\end{array}$ \\
\hline Bolger et al., 1997 & 832 & 42.1 & 672.8 & 83.97 & 1 & A & 0.5616 \\
\hline Chiarello, 1999 & 509 & 11005.0 & 103.8 & 21590 & 2.5 & A & 0.4523 \\
\hline Cox, 2004 & NA & 34.5 & 460 & 68.8 & 3 & A & 0.6246 \\
\hline Dunstan and Fox, 1996 & 212 & 14.7 & 97.2 & 28.88 & 3 & A & 0.3992 \\
\hline Happold and Happold, 1997 & 180 & 13325.0 & 65.6 & 25850 & 3 & A & 0.4345 \\
\hline Harrington et al., 2001 & 2255 & 50.0 & 32.3 & 94 & 3 & A & 0.6667 \\
\hline Kelt, 2000 & 1208 & 63.3 & 66.0 & 123 & 2 & A & 0.5929 \\
\hline Laidlaw, 2000 & NA & 5035.0 & 142.8 & 9930 & 5 & A & 0.7257 \\
\hline Lomolino and Perault, 2001 & NA & 22.9 & 48.3 & 44.04 & 6 & A & 0.6491 \\
\hline Mortelliti and Boitani, 2008 & NA & 40.1 & 194.7 & 79.4 & 3 & A & 0.4058 \\
\hline Mortelliti and Boitani, 2009 & 170 & 51.0 & 317.8 & 101.4 & 3 & A & 0.3699 \\
\hline Rosenblatt et al., 1999 & NA & 300.9 & 333.3 & 598.2 & 3 & A & 0.7686 \\
\hline Silva and Prince, 2008 & 1011 & 7.1 & 1.9 & 4.7 & 3 & $\mathrm{P}$ & 0.5988 \\
\hline Sridhar et al., 2008 & NA & 1092.5 & 10.8 & 1815 & 4.33 & A & 0.9363 \\
\hline Sridhar et al., 2008 & NA & 62.3 & 2.8 & 59.4 & 4 & A & 0.8841 \\
\hline Stone et al., 2008 & NA & 7600.0 & 75.0 & 14800 & 3.67 & A & 0.8200 \\
\hline Umapathy and Kumar, 2000 & NA & 1249.0 & 2498.0 & 2498 & 3 & $\mathrm{P}$ & 0.4677 \\
\hline $\begin{array}{l}\text { Viveiros de Castro and } \\
\text { Fernandez, } 2004\end{array}$ & 4075 & 7.2 & 11.0 & 12.1 & 4 & A & 0.7317 \\
\hline Passamani, 2003 & 654 & 100.2 & 70.5 & 194.8 & 3.33 & A & 0.8815 \\
\hline
\end{tabular}

Table 2 - Results of the simple regressions, showing the effect of each variable alone in the NODF index of nestedness. As indicated, only ratio had a significant effect, respectively. Logarithm was employed in an attempt to normalise independent variables, and assure that all studies had values on the same scale $\left(10^{\wedge} 1\right)$.

\begin{tabular}{lccccc}
\hline Model & Coefficient & $\mathbf{R}^{2}$ & $\mathbf{n}$ & $\mathbf{F}$ & $\mathbf{p ~ v a l u e ~}$ \\
\hline row nestedness $\sim \log ($ trapnights $)$ & 0.04162 & 0.1502 & 14 & 2.121 & 0.1709 \\
row nestedness $\sim \log ($ kilometer walked in transects) & -0.01124 & 0.01407 & 11 & 0.1285 & 0.7283 \\
row nestedness $\sim \log ($ size range) & -0.007434 & 0.01118 & 24 & 0.2488 & 0.6228 \\
row nestedness $\sim \log ($ mean area) & -0.005689 & 0.005938 & 24 & 0.1314 & 0.7204 \\
row nestedness $\sim \log ($ size ratio) & $\mathbf{- 0 . 0 4 6 8 6}$ & $\mathbf{0 . 2 3 9 5}$ & $\mathbf{2 4}$ & $\mathbf{6 . 9 3}$ & $\mathbf{0 . 0 1 5 2}$ \\
row nestedness $\sim \log ($ time since isolation $)$ & -0.006446 & 0.001358 & 16 & 0.01903 & 0.8922 \\
row nestedness $\sim$ matrix index & 0.05109 & 0.09681 & 24 & 2.358 & 0.1389 \\
row nestedness $\sim$ presence of corridors & -0.08903 & 0.02075 & 24 & 0.4663 & 0.5018 \\
\hline
\end{tabular}

and nestedness. Multi-taxa analyses have also found this relation, but with positive correlations (Watling and Donnelly, 2006; Wright et al., 1998). This difference might result from the spatial scale of our work. It is possible that the fragments analysed were distant enough to promote a turnover of species. Therefore, nestedness would be low. However, this paper only has data to describe the pattern, not the process. We think that size ratio is often the best way of expressing the effect of size variation on nestedness. 
The last variable inserted in the model was the presence or absence of corridors, whose effect on nestedness had not been directly tested before. Our results indicate that corridors do not affect nestedness.

Although several reviews have analysed nestedness across taxa (Watling and Donnelly, 2006; Wright et al., 1998), this is the first one to focus only on mammalian communities in fragmented landscapes. Our finding that nestedness was not related to matrix type or to the presence of corridors hinders nestedness as an indicator of anthropogenic disturbance, and therefore its use as in reserve design (Boecklen, 1997; Donlan et al., 2005). We also found that variation in size (size ratio) affects nestedness (as Watling and Donnelly 2006 and Wright et al., 1998 also found out), but the absolute area value (that is, the spatial scale) does not. We also found that nestedness is independent of effort. These results, when brought together, indicate that nestedness might be independent of scale. However, this is only true if the metric is insensitive to community fill and size. Therefore we support the use of standardised NODF as a nestedness metric for mammals and provide evidence that equiprobable null models are recommended in analysis with mammals.

\section{Acknowledgments}

To all colleagues who helped in field work and with data analysis for the dataset we produced. We are greatly in debt to Alexandra Pires, Marcelo Passamani and to Ernesto Viveiros de Castro, for his contribution to the previous versions of this article. We also thank the Fundação O Boticário de Proteção à Natureza for funding, and PIBIC-SR2-UFRJ and CNPq for personal grants for the first two authors.

\section{References}

ALMEIDA-NETO M., GUIMARÃES, PR., GUIMARÃES JUNIOR, PR., LOYOLA, RD. and ULRICH, W., 2008. A consistent metric for nestedness analysis in ecological systems: reconciling concept and measurement. Oikos, vol. 117, p. 1-13.

BOECKLEN, WJ., 1997. Nestedness, biogeographic theory, and the design of nature reserves. Oecologia, vol. 112, p. 123-142.

BOLGER, DT., ALBERTS, AC., SAUVAJOT, RM., POTENZA, P., MCCALVIN, C., TRAN, D., MAZZONI, S. and SOULE, ME., 1997. Response of rodents to habitat fragmentation in coastal southern California. Ecological Applications, vol. 7, p. 552-563.

CHIARELLO, AG., 1999. Effects of fragmentation of the Atlantic Forest on mammal communities in south-eastern Brazil. Biological Conservation, vol. 89, p. 71-82.

COX, M., 2004. Effects of rainforest fragmentation on nonflying mammals of the eastern Dorrigo Plateau, Australia. Biological Conservation, vol. 115, p. 175-189.

CUTLER, A., 1991. Nested faunas and extinction in fragmented habitats. Conservation Biology, vol. 5, p. 496-505.

-, 1994. Nested biotas and biological conservation - metrics, mechanisms, and meaning of nestedness. Landscape and Urban Planning, vol. 28, p. 73-82.

DONLAN, CJ., KNOWLTON, J., DOAK, DF. and BIAVASCHI, N., 2005. Nested communities, invasive species and holocene extinctions, p. evaluating the power of a potential conservation tool. Oecologia, vol. 145, p. 475-485.

DUNSTAN, CE. and FOX, BJ., 1996. The effects of fragmentation and disturbance of rainforest on ground-dwelling small mammals on the Robertson plateau, New South Wales, Australia. Journal of Biogeography, vol. 23, p. 187-201.

FISCHER, J. and LINDENMAYER, D.B., 2005. Nestedness in fragmented landscapes: a case study on birds, arboreal marsupials and lizards. Journal of Biogeography, vol. 32, p. $1737-1750$.

FRANKLIN, JF. and LINDENMAYER, DB., 2009. Importance of matrix habitats in maintaining biological diversity. Proceedings of the National Academy of Science, vol. 106, p. 349-350.

GANZHORN, JU. and EISENBEISS, B., 2001. The the concept of nested species assemblages and its utility for understanding effects of habitat fragmentation. Basic and Applied Ecology, vol. 2, p. 87-99.

GASCON, C., LOVEJOY, TE., BIERREGAARD, RO., MALCOLM, JR., STOUFFER, PC., VASCONCELOS, HL., LAURANCE, WF., ZIMMERMAN, B., TOCHER, M. and BORGES, S., 1999. Matrix habitat and species richness in tropical forest remnants. Biological Conservation, vol. 91, p. 223-229.

GILBERT-NORTON, L., WILSON, R., STEVENS, JR. and BEARD, KH., 2010. A meta-analytic review of corridor effectiveness. Conservation Biology, vol. 24, p. 660-668.

GUIMARÃES JUNIOR, PR. and GUIMARÃES, P., 2006. Improving the analyses of nestedness for large sets of matrices. Environmental Modeling and Software, vol. 21, p. 1512-1513.

HAPPOLD, DCD. and HAPPOLD, M., 1997. Conservation of mammals on a tobacco farm on the highlands of Malawi. Biodiversity and Conservation, vol. 6, p. 837-852.

HARRINGTON, GN., FREEMAN, AND. and CROME, FHJ., 2001. The effects of fragmentation of an Australian tropical rain forest on populations and assemblages of small mammals. Journal of Tropical Ecology, vol. 17, p. 225 240.

KELT, DA., 2000. Small mammal communities in rainforest fragments in central southern Chile. Biological Conservation, vol. 92, p. 345-358.

LAIDLAW, RK., 2000. Effects of habitat disturbance and protected areas on mammals of peninsular Malaysia. Conservation Biology, vol. 14, p. 1639-1648.

LAURANCE, WF., 1991. Ecological correlates of extinction proneness in australian tropical rain-forest mammals. Conservation Biology, vol. 5, p. 79-89.

LOMOLINO, MV. and PERAULT, DR., 2001. Island biogeography and landscape ecology of mammals inhabiting fragmented, temperate rain forests. Global Ecology \& Biogeography, vol. 10, p. 113-132.

MacARTHUR, R. H. and WILSON, EO., 1967. The theory of island biogeography. Princeton: Princeton University Press. 203 p.

MARTINEZ-MORALES, MA., 2005. Nested species assemblages as a tool to detect sensitivity to forest fragmentation: the case of cloud forest birds. Oikos, vol. 108, p. 634-642.

McDONALD, KA. and BROWN, JH., 1992. Using montane mammals to model extinctions due to global change. Conservation Biology, vol. 6, p. 409-415.

MEYER, CFJ. and KALKO, EKV., 2008. Bat assemblages on Neotropical land-bridge islands: nested subsets and null 
model analyses of species co-occurrence patterns. Diversity and Distributions, vol. 14, p. 644-654.

MORTELLITI, A. and BOITANI, L., 2008. Evaluation of scent-station surveys to monitor the distribution of three european carnivore species (martes foina, meles meles, vulpes vulpes) in a fragmented landscape. Mammalian Biology-Zeitschrift fur Saugetierkunde, vol. 73, p. 287-292.

-, 2009. Distribution and coexistence of shrews in patchy landscapes: A field test of multiple hypotheses. Acta Oecologica, vol. 35, p. 797-804.

NIELSEN, A. and BASCOMPTE, J., 2007. Ecological networks, nestedness and sampling effort. Journal of Ecology, vol. 95, p. 1134-1141.

PASSAMANI, M., 2003. O efeito da fragmentação da mata atlântica serrana sobre a comunidade de pequenos mamíferos de Santa Teresa, Espírito Santo. Rio de Janeiro: Universidade Federal do Rio de Janeiro. 105 p. Tese de Doutorado em Ecologia.

PATTERSON, BD., 1987. The principle of nested subsets and its implications for biological conservation. Conservation Biology, vol. 1, p. 323-334.

-, 1990. On the temporal development of nested subset patterns of species composition. Oikos, vol. 59, p. 330-342.

PATTERSON, BD. and ATMAR, W., 1986. Nested subsets and the structure of insular mammalian faunas and archipelagos. Biological Journal of the Linnean Society, vol. 28, p. $65-82$.

PREVEDELLO, JA. and VIEIRA, MV., 2009. Does the type of matrix matter? A quantitative review of the evidence. Biodiversity and Conservation, vol. 19, p. 1205-1223.

ROCHA, MF., PASSAMANI, M. and LOUZADA, J., 2011. A small mammal community in a forest fragment, vegetation corridor and coffee matrix system in the Brazilian Atlantic forest. PloS one, vol. 6, e23312.

ROSENBLATT, DL., HESKE, EJ., NELSON, SL., BARBER, DM. and MACALLISTER, MAMAB., 1999. Forest fragments in east-central Illinois: islands or habitat patches for mammals? American Midland Naturalist, vol. 141, p. 115-123

NUPP, TE. and SWIHART, RK., 2000. Landscape-Level Correlates of Small-Mammal Assemblages in Forest Fragments of Farmland. Journal of Mammalogy, vol. 81, p. 512-526.

SILVA, M. and PRINCE, ME., 2008. The conservation value of hedgerows for small mammals in Prince Edward Island,
Canada. American Midland Naturalist, vol. 159, p. 110124.

SRIDHAR, H., RAMAN, TRS. and MUDAPPA, D., 2008. Mammal persistence and abundance in tropical rainforest remnants in the southern Western Ghats, India. Current Science, vol. 94, p. 748-757.

STONE, AI., LIMA, EM., AGUIAR, GFS., CAMARGO, CC., FLORES, TA., KELT, DA., MARQUES-AGUIAR, SA., QUEIROZ, JAL., RAMOS, RM. and SILVA JÚNIOR, JS., 2008. Non-volant mammalian diversity in fragments in extreme eastern Amazonia. Biodiversity and Conservation, vol. 18, p. 1685-1694.

TORRE I., ARRIZABALAGA, A. and FLAQUER, C., 2004. Three methods for assessing richness and composition of small mammal communities. Journal of Mammalogy, vol. 85:524-530.

UMAPATHY, G. and KUMAR, A., 2000. The occurrence of arboreal mammals in the rain forest fragments in the Anamalai Hills, south India. Biological Conservation, vol. 92, p. 311-319.

ULRICH, W., ALMEIDA-NETO, M. and GOTELLI, N. J., 2009. A consumer's guide to nestedness analysis. Oikos, vol. 118, p. 3-17.

VIVEIROS DE CASTRO, EB. and FERNANDEZ, FAS., 2004. Determinants of differential extinction vulnerabilities of small mammals in Atlantic Forest fragments in Brazil. Biological Conservation, vol. 119, p. 73-80.

WANG, Y., BAO, Y., YU, M., XU, G. and DING, P., 2010. Nestedness for different reasons: the distributions of birds, lizards and small mammals on islands of an inundated lake. Diversity and distributions, vol. 16, p. 862873.

WATLING, JI. and DONNELLY, MA., 2006. Fragments as islands: A synthesis of faunal responses to habitat patchiness. Conservation Biology, vol. 20, p. 1016-1025.

WATLING, JI., GEROW, K. and DONNELLY, MA., 2009. Nested species subsets of amphibians and reptiles on Neotropical forest islands. Animal Conservation, vol. 12, p. 467-476.

WORTHEN, WB., 1996. Community composition and nestedsubset analyses: basic descriptors for co mmunity ecology. Oikos, vol. 76, p. 417-426.

WRIGHT, DH., PATTERSON, BD., MIKKELSON, GM., CUTLER, A. and ATMAR, W., 1998. A comparative analysis of nested subset patterns of species composition. Oecologia, vol. 113, p. 1-20. 